\title{
Model Matematika Konflik Tiga Kompartemen (Model Diskret)
}

\author{
Sugiyanto dan Muhammad Wakhid Musthofa \\ Program Studi Matematika, Fakultas Sains dan Teknologi, UIN Sunan Kalijaga, JI. Marsda Adisucipto \\ No. 1 Yogyakarta, Indonesia \\ Korespondensi; Sugiyanto, Email: sugimath@yahoo.co.id
}

\begin{abstract}
Abstrak
Konflik antar kelompok masyarakat merupakan masalah serius bagi masyarakat Indonesia. Model Matematika mencoba menyelesaikan masalah ini. Dalam penelitian ini jumlah petugas kepolisian yang terlibat telah sesuai dengan jumlah kekuatan sekelompok pihak yang bertikai, sehingga polisi dapat meringankan masyarakat karena besarnya daya yang seimbang. Dalam studi kasus konflik di Lampung Selatan sebanyak 700 petugas kepolisian yang telah dilibatkan sudah sesuai. Korban meninggal karena polisi terlambat menerjunkan 700 polisi.
\end{abstract}

Kata Kunci: Konflik; Model matematika

\begin{abstract}
The conflict between groups of people is a serious problem for the people of Indonesia. Mathematical Model of trying to resolve this problem. In this study the number of police officers involved have been in accordance with the amount of power a group of warring parties, so that the police can relieve the community because the amount of power that is balanced. In the case study of conflicts in South Lampung as much as $\mathbf{7 0 0}$ police officers who have been involved is in compliance. The victim died because police were too late in fielded as many as 700 police.
\end{abstract}

Keywords: Conflict; Mathematical model

\section{Pendahuluan}

Hidup di tengah komunitas dengan keragaman agama, suku dan budaya adalah keniscayaan yang tidak dapat dipungkiri oleh bangsa Indonesia. Keragaman tersebut di satu sisi merupakan kelebihan dan kekayaan yang dimiliki oleh bangsa Indonesia. Namun di sisi lain, tata kehidupan berbangsa dengan keragaman agama, suku dan budaya yang berhubungan dengan interaksi antargolongan mengandung potensi konflik yang besar.

Konflik sosial yang terjadi di beberapa daerah di Indonesia pada lebih dari dua dasawarsa terakhir lalu, baik dalam eskalasi besar maupun kecil telah membawa korban jiwa manusia, harta, sumber mata pencaharian dan lainnya, sehingga menghancurkan sendi-sendi kemanusian dan kebangsaan Indonesia. Nampaknya kerusuhan yang berlatar belakang sosial dan agama tersebut telah menjadi gejala yang umum bagi perjalanan hidup bangsa ini. Menjelang penghujung abad 20 tercatat terjadi beberapa kali peristiwa konflik yang bernuansa sosial maupun agama, seperti kerusuhan di Situbondo tanggal 10 Oktober 1996, di Tasikmalaya 26 Desember 1996, di Karawang tahun 1997 dan Tragedi Mei pada tanggal 13, 15 Mei 1998, yang terjadi di Jakarta, Solo, Surabaya, Palembang, Medan, bentrokan berdarah di makam Mbah priok tahun 2010, beserta peristiwa-peristiwa kerusuhan lainnya. Demikian beberapa rentetan terjadinya kerusuhan di Indonesia yang lebih condong bernuansa sosial.

Kerusuhan sosial yang bernuansa agama pun bermunculan di Indonesia pada dasawarsa terakhir lalu, yang banyak menelan korban jiwa, harta dan mematahkan sendi-sendi kehidupan masyarakat dan agama di negeri ini. Dunia terhentakkan dengan peristiwa-peristiwa kerusuhan yang memilukan, sekaligus mengecewakan dan banyak memakan korban. Beberapa kasus yang menghentakkan 
diantaranya konflik Ambon-Lease tahun 1999, konflik masyarakat dengan penganut Ahmadiyah tahun 2008 2010, dan lain-lain.

Model matematika adalah salah satu konsentrasi keilmuan dalam matematika yang berusaha mendekati dan menerjemahkan suatu fonomena dalam kehidupan ke dalam bentuk persamaan matematika yang menggambarkan fenomena tersebut. Dengan menyelesaikan model matematika akan dihasilkan rekomendasi-rekomendasi solusi dar masalah yang dimodelkan.

Beberapa matematikawan telah memperkenalkan model matematika yang merepresentasikan konflik yang terjadi antar elemen di masyarakat. Salah satunya adalah Richardson (1960). Richardson memodelkan konflik yang terjadi antara dua elemen masyarakat dengan memilih jumlah anggota kelompok yang berkelahi dan senjata yang dimiliki masing-masing kelompok sebagai variabel utama dalam pemodelan. Di samping itu, Richardson juga memasukkan dukungan politik dari pihak yang berkuasa sebagai variabel penentu. [1]

Model matematika yang ditawarkan oleh Richardson masih sederhana dan masih dapat dikembangkan. Hal ini disebabkan variabel yang menyusun model tersebut belumlah sesuai dengan konteks ke-Indonesia-an sehingga model tersebut tidak cocok digunakan untuk menggambarkan situasi konflik sosial dan agama yang terjadi di Indonesia. Oleh karena itu, penelitian ini bermaksud mengembangkan model matematika Richardson dengan jalan merumuskan variabel-variabel real yang mempengaruhi konflik sosial dan agama di Idonesia dan mengestimasi variabel-variabel tersebut. Diharapkan dengan pemgembangan model ini akan diperoleh model yang lebih relevan dan dapat lebih menggambarkan situasi konflik sosial dan agama yang terjadi di Indonesia. Sehingga dengan demikian diharapkan dapat dirumuskan solusi-solusi alternatif untuk menyelesaikan berbagai konflik sosial dan agama yang terjadi.

\section{Pembahasan}

\section{Model Matematika}

Kita akan mempertimbangkan sistem pada tiga kelompok yang bertikai, dinotasikan A, B, dan C.

- A adalah sangat ingin bertikai dan cenderung bertikai.

- B adalah netral dan lebih pasif.

- C adalah enggan memusui kelompok A.

Misalkan kita memasangkan variabel $x, y$, dan $z$ mereka berturut-turut, yang mana mengindikasikan jumlah kekuatan yang kelompok punyai. Mudah mengukur unit dari kekuatan setiap kelompok yang dipunyai jika diketahui jumlah orang masing-masing yang bertiakai, polisi, dan senjata yang mereka gunakan.

Model Matematika ini, jumlah kekuatan pada kelompok pada waktu $t=k+1$ (pertikaian $k+1$ ) bergantung pada empat dasar berikut.

1. Jumlah kekuatan yang mereka siapkan pada waktu $t=k$.

2. Jumlah kekuatan yang mungkin akan dibangun adalah merespon level kekuatan kelompok lain.

3. Jika mendatangi lawan 0,5 dan didatangi lawan bernilai 1 .

4. Jika menggunakan pedang, bambu runcing 0,5 dan pistol 1 .

Disini ada empat dasar kita mengijinkan mensusun sistem berikut yang terdiri dari tiga persamaan untuk tiga asumsi dari kelompok-kelompok tersebut.

$$
\begin{aligned}
x_{k+1} & =f_{1} x_{k}+a_{12} y_{k}+a_{13} z_{k}+g_{1} \\
y_{k+1} & =f_{2} y_{k}+a_{21} y_{k}+a_{23} z_{k}+g_{2} \\
z_{k+1} & =f_{3} z_{k}+a_{31} x_{k}+a_{32} y_{k}+g_{2}
\end{aligned}
$$

Dengan $f_{i}$ adalah Koefisien Keletihan (Fatique Coeffisients) yang diwakili item nomer 3 di atas, $g_{i}$ adalah Masa Keluhan (Grievance Term) yang diwakili item nomer 4 di atas, dan $a_{i j}$ mewakili respon 
kekuatan kelompok $i$ terhadap level kelompok $j$. Untuk tiga kelompok yang kita gambarkan di atas, kita mungkin menghimpun nilai berikut. [2]

- Nilai $g_{2}=0$ karena kelompok B netral atau tidak menggunakan senjata dan $g_{1}$ dan $g_{3}$ tidak sama dengan nol, defininya adalah sebagai berikut Bernilai 0,5 jika senjata-senjata pedang, bambu runcing dan bernilai 1 jika menggunakan pistol.

- Nilai $a_{12}=0$, karena kelompok $\mathrm{A}$ tidak bermusuhan dengan kelompok $\mathrm{B}$, dan $a_{32}=0$ karena kelompok $\mathrm{C}$ dan kelompok $\mathrm{B}$ bukan musuh dan nilai untuk $a_{13}$ dan $a_{31}$ tidak sama dengan nol, ini tergantung jumlah orang masing-masing kelompok.

- Kita mungkin juga menilai $f_{i}=0,5, f_{2}=0$, dan $f_{3}=1$, karena kelompok A mendatangi kelompok C, karena kelompok B tidak mendatangi pihak manapun, dan karena kelompok C didatangi kelompok A.

- Kita menilai $a_{31}=1$ yang mengindikasikan kelompok $C$ selalu membangun kekuatan jika kelompok A melakukan. Pada sisi lain, kita menilai $a_{31}=1,2$ mengindikasikan kelompok $C$ selalu membangun $20 \%$ lebih kekuatan daripada kelompok A punyai.

Jika persamaan (1) dibentuk matriks maka diperoleh,

$$
\left(\begin{array}{l}
x_{k+1} \\
y_{k+1} \\
z_{k+1}
\end{array}\right)=\left(\begin{array}{ccc}
f_{1} & a_{12} & a_{13} \\
a_{21} & f_{2} & a_{23} \\
a_{31} & a_{32} & f_{3}
\end{array}\right)\left(\begin{array}{l}
x_{k} \\
y_{k} \\
z_{k}
\end{array}\right)+\left(\begin{array}{l}
g_{1} \\
g_{2} \\
g_{3}
\end{array}\right)
$$

atau dapat ditulis,

$$
X_{k+1}=A X_{k}+g
$$

dengan matrik $A$ adalah

$$
A=\left(\begin{array}{ccc}
f_{1} & a_{12} & a_{13} \\
a_{21} & f_{2} & a_{23} \\
a_{31} & a_{32} & f_{3}
\end{array}\right)
$$

dan vektor $g$ adalah

$$
g=\left(\begin{array}{l}
g_{1} \\
g_{2} \\
g_{3}
\end{array}\right)
$$

\section{Kondisi Steady State}

Model ini pada kondisi steady state, nilai kekuatan tidak berubah. Ini dapat terjadi jika $X_{k+1}=X_{k}$. Untuk menghitung jika ini dapat terjadi, Kita menunjukkkan kondisi vektor steady state $X_{s}$ dan kita dapat menyelesaikan persamaan ini.

$$
X_{s}=A X_{s}+g
$$

yang mana dapat ditulis dengan lebih familier sebagai

$$
\left(I_{n}-A\right) X_{s}=g
$$

Setelah mencari $X_{S}$, persamaan ini adalah kita definisikan sebagai berikut.

1. Nilai $\left|y_{s}-x_{s}\right|<0,5$ tidak perlu penambahan jumlah orang kelompok B untuk meredam pertikaian kelompok A. 
2. Nilai $\left|y_{s}-x_{s}\right| \geq 0,5$ perlu penambahan jumlah orang kelompok B untuk meredam pertikaian kelompok A.

3. Nilai $\left|y_{s}-z_{s}\right|<0,5$ tidak perlu penambahan jumlah orang kelompok B untuk meredam pertikaian kelompok C.

4. Nilai $\left|y_{s}-z_{s}\right| \geq 0,5$ perlu penambahan jumlah orang kelompok B untuk meredam pertikaian kelompok C.[3]

Dengan pendekatan yang lain kita menyelidiki model dengan menghitung nilai $X_{k}$ untuk pertikaian/bentrokan $k=1,2,3, \ldots$. Kita dapat menghasilkan persamaan barisan berikut.

$$
\begin{aligned}
& X_{1}=A X_{0}+g \\
& X_{2}=A X_{1}+g=A\left(A X_{0}+g\right)+g=A^{2} X_{0}+A g+g \\
& X_{3}=A X_{2}+g=A\left(A^{2} X_{0}+A g+g\right)=A^{3} X_{0}+A^{2} g+A g+g
\end{aligned}
$$

atau secara umum ditulis,

$$
X_{k}=A^{k} X_{0}+A^{k-1} g+\ldots+A g+g
$$

Seseorang dapat membayangkan hasil sesuai yang disimulasi berikut.

1. Besarnya $X_{k}$ mungkin menuju tak hingga, mengindikasikan perlombaan kekuatan tidak terkendali.

2. Vektor $X_{k}$ mungkin menuju steady state, mengindikasikan situasi dapat terkendali.

3. Vektor $X_{k}$ mungkin menuju nol, mengindikasikan situasi perdamaian. [4]

\section{Studi Kasus: Konflik Antar Warga Di Kalianda, Lampung Selatan [5]}

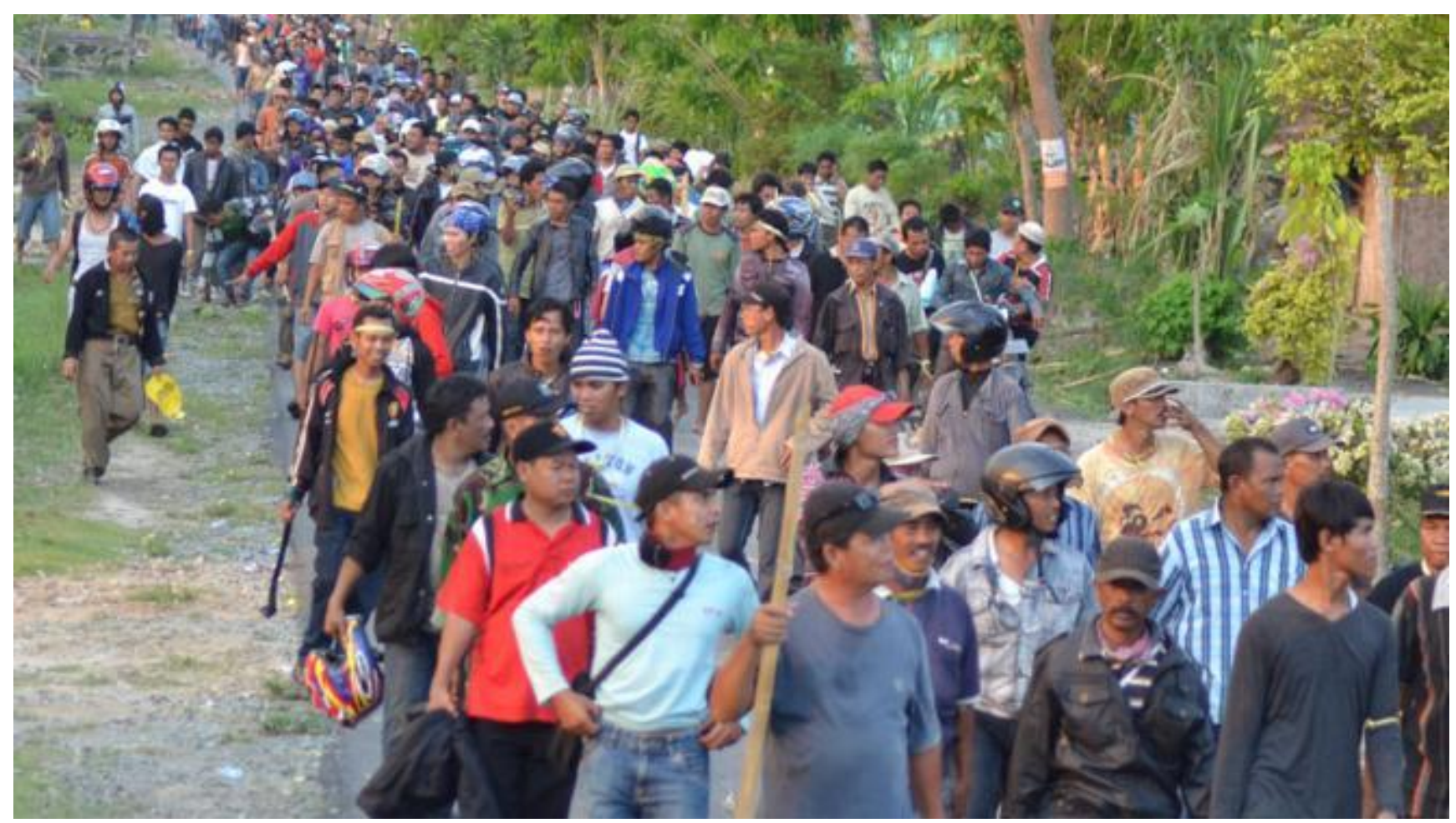

Gambar 1 Ribuan Orang Usai Menyerang Desa Balinuraga, Lampung Selatan.

Total korban tewas dalam bentrokan di Lampung Selatan yang terjadi selama dua hari berjumlah 10 orang. Sebanyak 8 orang lainnya mengalami luka-luka. Saat ini, ada 1.108 jiwa masih dalam pengungsian akibat penyerangan ke desa Balinuraga, kecamatan Way Panji. 


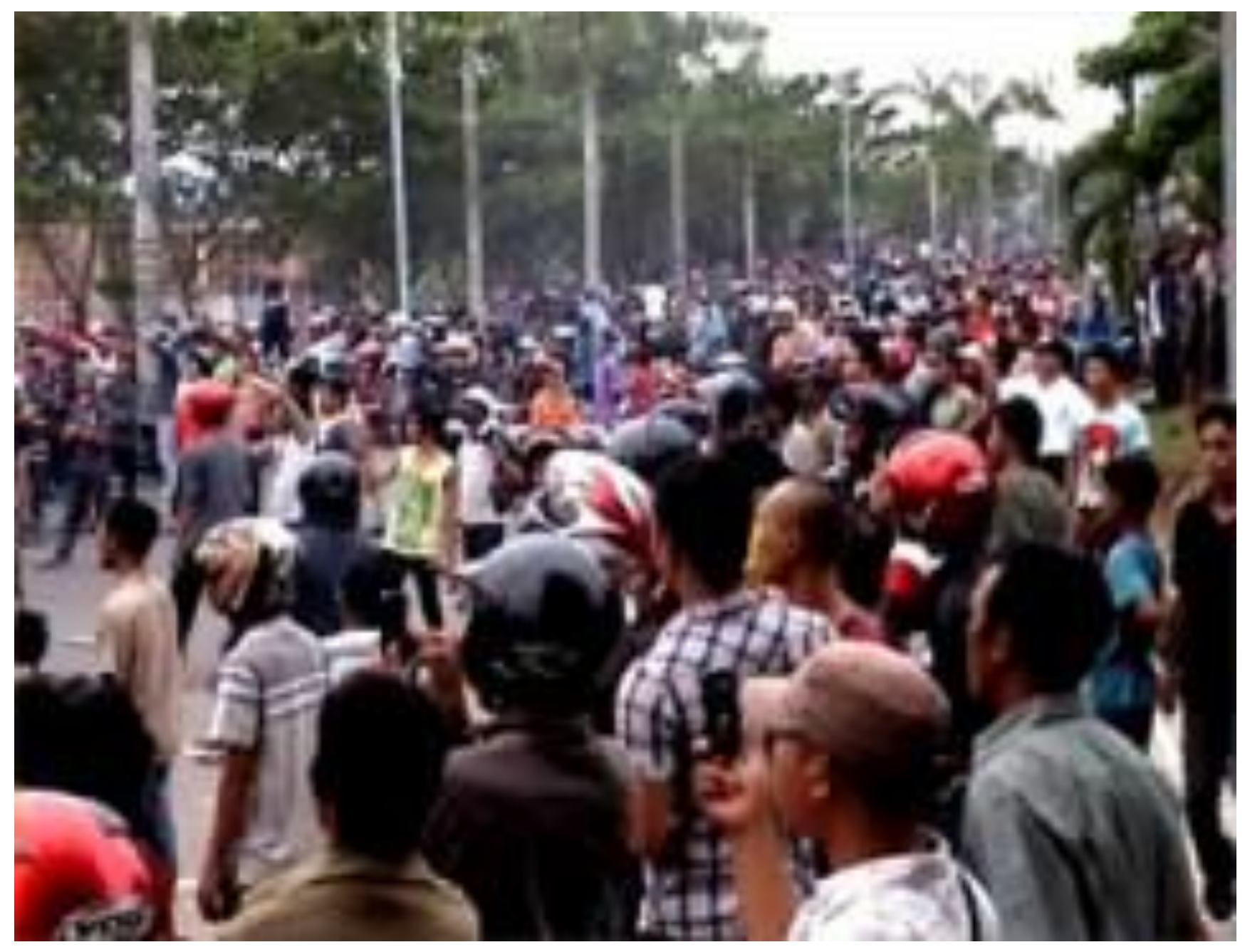

Gambar 2 Ribuan Warga Terlibat Penyerangan dan Pembakaran Rumah di Desa Balinuraga, Kecamatan Kalianda, Lampung Selatan.

"10 Orang ditemukan tewas pasca-kejadian, termasuk pada satu hari sebelumnya tiga orang. Kemarin ada 6 orang tewas, ditambah satu orang ditemukan di rumah sakit saat evakuasi," kata Kepala Biro Penerangan Masyarakat Polri, Brigadir Jenderal Polisi Boy Rafli Amar di Jakarta, Selasa 30 Oktober 2012.

Menurut Boy, Polri menyesalkan terjadinya konflik antar warga di Kalianda, Lampung Selatan. Bentrokan yang bermula dipicu kasus kecelakaan lalu lintas. Kasus kecelakaan sepeda motor dan sepeda ontel yang melibatkan remaja putri dan kemudian disalahartikan.

"Ada pertolongan oleh warga, tapi berkembang isu menjadi pelecehan seksual," jelas Boy. Sebenarnya, kata Boy, provokasi isu pelecehan seksual yang berkembang menjadi bentrokan pertama pada Minggu itu sudah diredam dengan adanya pertemuan. "Namun, sepertinya ada kondisi yang memprovokasi dan mengakibatkan gerakan yang lebih massif lagi," sesal Boy.

Saat ini, ada 1.108 pengungsi yang terdata. Dari jumlah itu sebanyak 247 diantaranya merupakan anak-anak. Jumlah itu masih akan terus meningkat karena masih banyak kendaraan yang mengangkut pengungsi terus berdatangan.

Dari pendataan petugas, sebanyak 7 rumah rusak, 11 sepeda motor dibakar, 1 gedung sekolah dasar dibakar, 1 unit mobil minibus dan 2 unit mobil jip juga dibakar.

Polri mengerahkan Brimob Polda Banten dan Sumsel untuk menuju lokasi. Sebanyak 700 anggota TNI juga dikerahkan. "Kepolisian juga mengerahkan dari Polda dan Mako Brimob," tegas Boy. (ren)

Model Matematika:

$$
\left(I_{n}-A\right) X_{s}=g
$$


Kita misalkan $x$ adalah warga desa Anom, $y$ adalah kepolisian, dan $z$ adalah warga desa Balinuraga.

$$
a_{12}=0
$$

Ini karena warga desa Anom dan polisi bukan musuh.

Karena Jumlah yang mengungsi adalah 1.108 orang, maka kita andaikan jumlah itu merupakan satu istri dan dua anak, jadi jumlah laki-laki yang ikut bertikai dari warga $1.108 / 3=370$. Sehingga

$$
a_{13}=\frac{1.000}{1.000+370}=\frac{1.000}{1.370}=0,73
$$

karena jumlah warga desa Anom yang bertikai 1.000 sedangkan jumlah warga desa Balinuraga 370 .

Karena jumlah polisi 700 dan jumlah warga desa Anom 1.000, maka

$$
a_{21}=\frac{700}{700+1.000}=\frac{700}{1700}=0,41
$$

Sedangkan karena jumlah polisi 700 dan jumlah warga desa Balinugara 370, maka

$$
a_{23}=\frac{700}{700+370}=\frac{700}{1.070}=0,65
$$

Karena warga desa Balinuraga berjumlah 370 dan warga desa Anom 1.000, maka

$$
a_{31}=\frac{370}{370+1.000}=\frac{370}{1.370}=0,27
$$

sedangkan antara warga desa Anom dan polisi tidak ada permasalahanm maka

$$
a_{32}=0
$$

Karena warga desa Anom dan warga desa Balinugara pengunaan senjata sama, maka

$$
g_{1}=0,5
$$

dan

$$
g_{3}=0,5
$$

Sedangakan,

$$
g_{2}=0
$$

Ini karena walaupun polisi mempunyai pistol, tetapi cenderung tidak digunakan.

Kita menilai $f_{1}=0.5, f_{2}=0$, dan $f_{3}=1$, karena warga desa Anom mendatangi warga desa Balinuraga, karena polisi tidak mendatangi pihak manapun, dan karena warga desa Balinuraga didatangi warga desa Anom.

Matrik:

$$
\begin{gathered}
I_{3}=\left(\begin{array}{lll}
1 & 0 & 0 \\
0 & 1 & 0 \\
0 & 0 & 1
\end{array}\right) \\
A=\left(\begin{array}{ccc}
0,5 & 0 & 0,73 \\
0,41 & 0 & 0,65 \\
0,27 & 0 & 1
\end{array}\right) \\
g=\left(\begin{array}{c}
1 \\
0 \\
0,5
\end{array}\right)
\end{gathered}
$$

Akan dicari $X_{S}$ 
atau

$$
\left(I_{n}-A\right)=\left(\begin{array}{lll}
1 & 0 & 0 \\
0 & 1 & 0 \\
0 & 0 & 1
\end{array}\right)-\left(\begin{array}{ccc}
0,5 & 0 & 0,73 \\
0,41 & 0 & 0,65 \\
0,27 & 0 & 1
\end{array}\right)
$$

$$
\left(I_{n}-A\right)=\left(\begin{array}{ccc}
0,5 & 0 & -0,73 \\
-0,41 & 1 & -0,65 \\
-0,27 & 0 & 0
\end{array}\right)
$$

Kita cari invers matrik ini,

$$
\left(\begin{array}{ccc|ccc}
0,5 & 0 & -0,73 & 1 & 0 & 0 \\
-0,41 & 1 & -0,65 & 0 & 1 & 0 \\
-0,27 & 0 & 0 & 0 & 0 & 1
\end{array}\right)
$$

Kita tukar baris satu dengan baris tiga,

$$
\left(\begin{array}{ccc|ccc}
-0,27 & 0 & 0 & 0 & 0 & 1 \\
-0,41 & 1 & -0,65 & 0 & 1 & 0 \\
0,5 & 0 & -0,73 & 1 & 0 & 0
\end{array}\right)
$$

Kita bagi baris pertama dengan $-0,27$

$$
\left(\begin{array}{ccc|ccc}
1 & 0 & 0 & 0 & 0 & -3,7 \\
-0,41 & 1 & -0,65 & 0 & 1 & 0 \\
0,5 & 0 & -0,73 & 1 & 0 & 0
\end{array}\right)
$$

Kita tambahkan baris kedua dengan $(0,41)$ (baris pertama), dan kita tambahkan baris ketiga dengan (0,5)(baris pertama),

$$
\left(\begin{array}{ccc|ccc}
1 & 0 & 0 & 0 & 0 & -3,7 \\
0 & 1 & -0,65 & 0 & 1 & -1,5 \\
0 & 0 & -0,73 & 1 & 0 & 1,85
\end{array}\right)
$$

Kita bagi baris ketiga dengan $-0,73$

$$
\left(\begin{array}{ccc|ccc}
1 & 0 & 0 & 0 & 0 & -3,7 \\
0 & 1 & -0,65 & 0 & 1 & -1,5 \\
0 & 0 & 1 & -1,37 & 0 & -2,53
\end{array}\right)
$$

Kita tambahkan baris kedua dengan $(0,65)$ (baris ketiga)

$$
\left(\begin{array}{lll|ccc}
1 & 0 & 0 & 0 & 0 & -3,7 \\
0 & 1 & 0 & -0,89 & 1 & -3,14 \\
0 & 0 & 1 & -1,37 & 0 & -2,53
\end{array}\right)
$$

Jadi nilai dari,

$$
\left(I_{n}-A\right)^{-1}=\left(\begin{array}{ccc}
0 & 0 & -3,7 \\
-0,89 & 1 & -3,14 \\
-1,37 & 0 & -2,53
\end{array}\right)
$$


dan

$$
\begin{gathered}
X_{s}=\left(\begin{array}{ccc}
0 & 0 & -3,7 \\
-0,89 & 1 & -3,14 \\
-1,37 & 0 & -2,53
\end{array}\right)\left(\begin{array}{c}
0,5 \\
0 \\
0,5
\end{array}\right) \\
X_{s}=\left(\begin{array}{c}
-1,85 \\
-2 \\
-1,95
\end{array}\right)
\end{gathered}
$$

Kita ingin lihat bahwa

$$
\begin{gathered}
\left|y_{s}-x_{s}\right|=-2-(-1,85)|=|-2+1,85|=-0,15|=0,15 \\
\left|y_{s}-z_{s}\right|=|-2-(-1,95)|=|-2+1,95|=|0,05|=0,05
\end{gathered}
$$

Karena nilai

$$
\left|y_{s}-x_{s}\right|=0,15
$$

cukup kecil maka tidak perlu ada penambahan jumlah polisi untuk menjaga warga desa Anom untuk tidak menyerang warga Desa Balinuraga, sedangkan

$$
\left|y_{s}-z_{s}\right|=0,05
$$

cukup kecil artinya tidak perlu penambahan jumlah polisi menjaga warga desa Balinuraga menyerang warga desa Anom.

\section{Kesimpulan}

Dari pembahasan dapat disimpulkan bahwa:

1. Jika kelompok A dan C bertikai/terjadi konflik dan Misalkan kelompok B adalah polisi, maka

- Nilai $\left|y_{s}-x_{s}\right|<0,5$ tidak perlu penambahan jumlah orang kelompok B untuk meredam pertikaian kelompok A.

- Nilai $\left|y_{s}-x_{s}\right| \geq 0,5$ perlu penambahan jumlah orang kelompok B untuk meredam pertikaian kelompok $A$.

- Nilai $\left|y_{s}-z_{s}\right|<0,5$ tidak perlu penambahan jumlah orang kelompok B untuk meredam pertikaian kelompok C.

- Nilai $\left|y_{s}-z_{s}\right| \geq 0,5$ perlu penambahan jumlah orang kelompok B untuk meredam pertikaian kelompok $\mathrm{C}$.

Dengan $x_{s}, y_{s}, \mathrm{z}_{s}$ berturut-turut adalah Jumlah Kekuatan Kelompok A, B, C pada kondisi stady state.

2. Pada study kasus konflik antar warga di Kalianda, Lampung Selatan nilai

$$
\left|y_{s}-x_{s}\right|=0,15
$$

cukup kecil maka tidak perlu ada penambahan jumlah polisi untuk menjaga warga desa Anom untuk tidak menyerang warga Desa Balinuraga, sedangkan

$$
\left|y_{s}-z_{s}\right|=0,05
$$

cukup kecil artinya tidak perlu penambahan jumlah polisi menjaga warga desa Balinuraga menyerang warga desa Anom. Terjadinya korban jiwa di kelompok ini karena polisi dalam menerjunkan jumlah 700 orang sudah agak terlambat. 


\section{Referensi}

[1] Richardson, L. F. (1960a): Arms and Insecurity: A Mathematical Study of the Causes and Origins of War, Pittsburgh: Boxwood 1960.

[2] Richardson, L. F. (1960b): Statistics of Deadly Quarrels. (Quincy Wright, C.C. Lienau, eds) Pittsburgh: Boxwood Press 1960.

[3] Saperstein, A. M. (1988b): SDI a model for chaos, Bulletin of the Atomic Scientists 44, no. 8, October 1988, pp. 40 43.

[4] Scheffran, J. (1989): Strategic Defense, Disarmament, and Stability Modelling Arms Race Phenomena with Security and Costs under Political and Technical Uncertainties, Doctoral

[5] http://nasional.news.viva.co.id/news/read/363446-1-108-orang-warga-lampung-selatan-mengungsi 5 Mei 2011. 